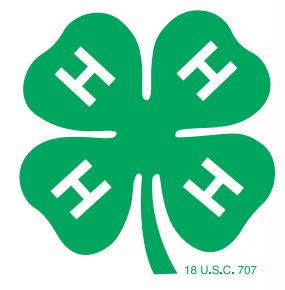

\title{
Online Learning Fact Sheet for the 4-H Youth Development Program Integrating Experiential Education into the Digital Realm
}

STEVEN M. WORKER, 4-H Youth Development Advisor, UC Agriculture and Natural Resources
O nline learning environments may provide opportunities for youth to develop their agency, competence, and belonging that are similar to the opportunities provided in physical learning environments. Youth development programs are well positioned to foster innovation for online learning that utilizes experiential education.

Experiential education-also known as hands-on learning and learning by doing-is a cycle composed of three phases: experience, reflection, and application (Kolb 1984).

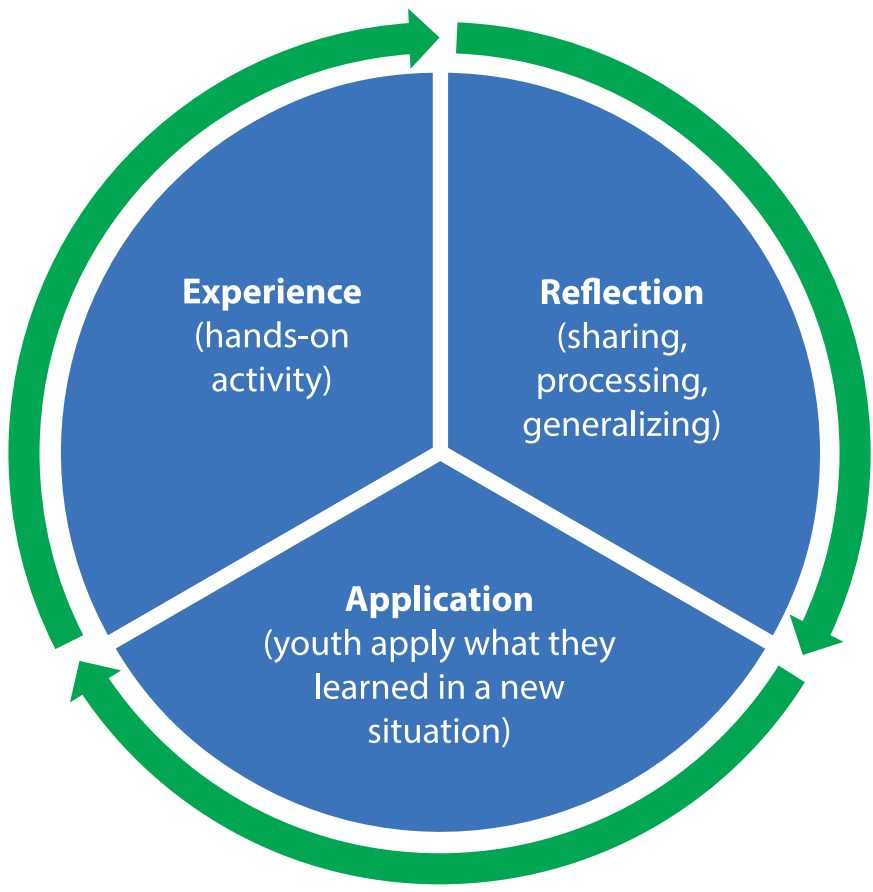

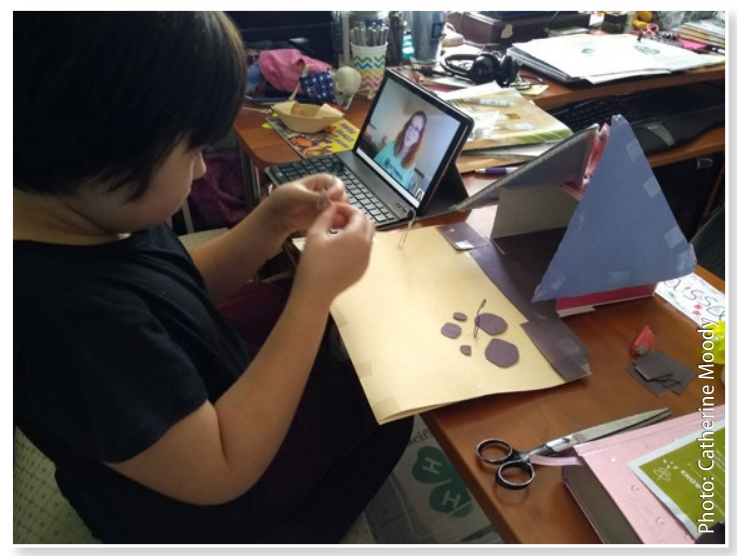

\section{Practices}

Experiential education may be implemented in online learning environments with adaptations to ensure core instructional principles are integrated (Carver 1996).

- Authenticity: Selection of hands-on activities relevant and meaningful to young people's lives; activities fit within constraints posed by online environments (e.g., materials are available at home, activities may be completed by one person and not require group work); educator provides scaffolding to assist youth in completing activities (e.g., regular opportunities to ask questions and receive feedback); occasions for adult, parental, and/or family involvement.

- Connection to the future: Educators ensure selection of activities most likely to support future learning. Youth reflect on their experience and how they might use what they have learned in the future. 
- Active learning: Youth are intellectually, emotionally, socially, and physically engaged in an active process of learning. Youth ask questions, use models, conduct investigations, analyze data, construct explanations, engage in discussion, and evaluate information. Practical educator practices (see box below) will strengthen active learning (Itin 1999).

- Drawing on previous experience: Youth connect activities to their previous experience. This is supported by the educator facilitating open-ended voice and video chat discussions synchronously and asynchronously through email, blogs, podcasts, videos, and social media.

\section{Practical Educator Practices}

- Select suitable experiences for online environment

- Set boundaries and expectations

- Ensure emotional safety

- Facilitate the learning process

- Guide reflection

\section{Outcomes}

When implemented well, experiential education in online environments will achieve similar outcomes to experiential education in physical environments (Lerner 2004).

- Agency: Allowing youth to become change agents in their own lives and in their communities.

- Competence: Development of mastery, including learning skills, deepening knowledge, participating to a fuller extent in community practices, and ability to apply experiences in new situations.

Type 1: Content Sharing

Educator distributes content; learners view content.
Type 2: Online Conversation In discussion forums, learners respond to prompts by the educator.
Type 4: Drawing on Learner Experiences Type 3: Meaningful Online Conversation Conversation emerges from the experiences and needs of learners.

Learners are actively objectives and
- Belonging: Development of a community in which youth have a place and see themselves as members. Establishing a sense of belonging is challenging in online communities, so the educator should take extra time to provide both informal and structured moments for connection, sharing, and discussion.

\section{Taxonomy of Experiential Online Learning}

The taxonomy illustrated below may be useful for educators in planning an online learning project. The lower levels may be considered as "passive" learning and the higher levels as more "active" learning (Carver et al. 2007).

\section{Examples of 4-H Online Learning Programs}

Educators should aim for the higher levels of learning in the taxonomy model. Examples follow of $4-\mathrm{H}$ online programs that engage these higher levels.

\section{Type 4: Rocketry project}

- Summary: Youth are involved in a hands-on rocket-building project at home. Meaningful discussions with peers and the educator happen both asynchronously and synchronously. This communication helps promote a sense of belonging and also competence in the content of aerospace, building/constructing models, and communicating online. involved in planning deciding on content.
Type 5:

Problem-Based / Service Learning

Course is constructed around a real issue; educator plans experiences.
Type 6: Action Learners bring their own issues to engage with; educator coaches and mentors. Learning 


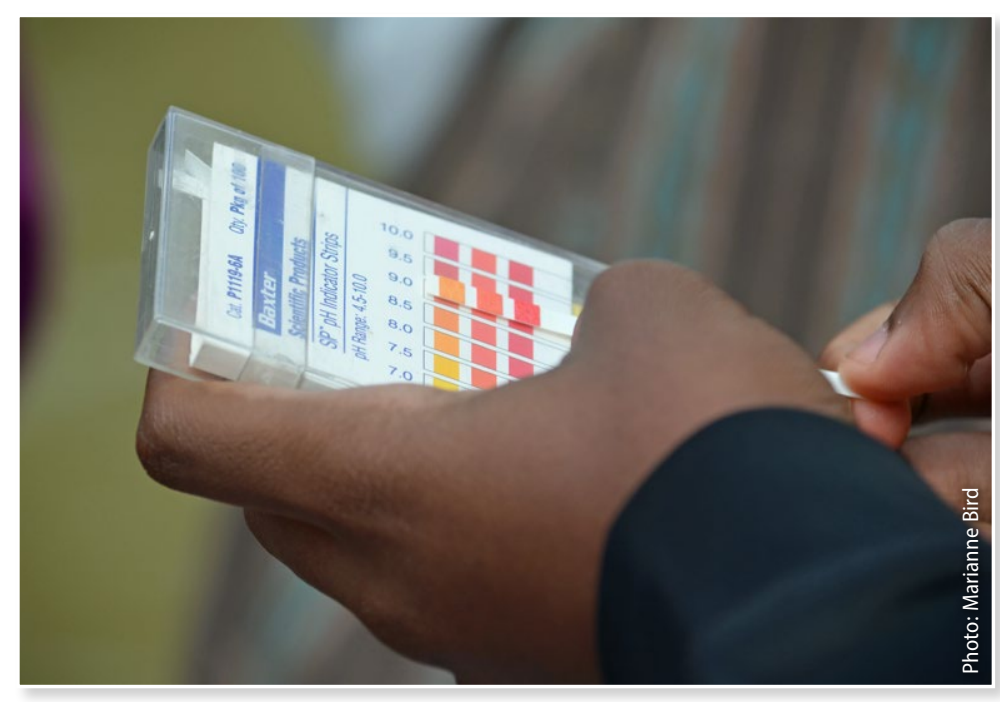

- Technology: The educator sets up monthly meetings using Zoom. Between meetings, the educator and youth communicate using a private ProBoards forum (discussion and messaging website).

- Meetings: Real-time, synchronous meetings take place once a month for an hour. The educator poses questions, facilitates discussion, and shares information. Between meetings, the educator and youth post on the forum.

- Learning experiences: At the beginning, youth are involved in a discussion of what they are interested in, what topics they would like to learn, and topics they would feel comfortable researching and sharing with others. During meetings, the educator poses questions, has youth watch videos and discuss, play an interactive game, or have youth share what they have been working on. Between meetings, youth are tasked to work on their model rocket. They post questions and messages to the online forum. Near the end, youth record a video of their rocket launch and post it online.

\section{Type 5: Environmental stewardship project}

- Summary: Youth are involved in learning about and contributing to the natural environment by conducting their own service-learning project informed through sharing and learning from the educator and peers. Active and authentic learning takes place as youth learn about environmental restoration and apply that knowledge to a real project in a local place. Youth bring their prior experience, collaborate, and learn that they can make a difference in their community.

- Technology: The educator sets up monthly meetings using Google Hangouts video calls and creates a private Facebook group.

- Meetings: Real-time, synchronous meetings take place twice a month for an hour. The educator poses questions, facilitates discussion, and shares information. Between meetings, the educator and youth post on the Facebook group.

- Learning experiences: At the beginning, youth meet regularly twice a month to discuss the environment, ecology, and other content involved in environmental restoration. The educator helps connect youth with organizations doing restoration work. Youth leave messages in the Facebook group to help one another plan. The educator and youth leave links there to websites and videos that display tips and ideas on how to restore native landscaping, irrigation, and related content. Each youth determines what environment they will restore-their backyard, local park, or other outdoor environment-and identifies and completes tasks there. At the end of the project, the educator facilitates a debriefing, helping youth evaluate their success, what could have worked better, and ideas for a future project.

\section{Type 6: Leadership project}

- Summary: Youth are involved in a leadership project without an explicit content learning goal. Instead, youth learn by planning and implementing a service project together to benefit an organization or community. Actively planning, implementing, and evaluating a service project combines meaningful learning with leadership development. Youth develop agency, a sense of belonging in a community of practice, and competence in both the subject matter and in teamwork, organization, and coordination.

- Technology: The educator provides a Zoom video meeting room, and creates a GroupMe text message group.

- Meetings: Real-time, synchronous meetings take place once a month for 2 hours. The facilitator role rotates between youth in the group. Youth text each other via a group chat between meetings. 
- Learning experiences: The educator helps provide the initial structure and group formation (e.g., introductions, ground rules, decision-making process, etc.). The educator takes a back seat and helps by offering suggestions and reflection questions. Youth spend time asynchronously texting the group with ideas and questions. At scheduled times, youth communicate synchronously to discuss these ideas, select a service project that is meaningful to them, plan the project, implement the project, and evaluate their impact.

\section{References}

Carver, R. 1996. Theory for practice: A framework for thinking about experiential education. Journal of Experiential Education 19(1): 8-13.

Carver, R., R. King, W. Hannum, and B. Fowler. 2007. Toward a model of experiential e-learning. Journal of Online Learning and Teaching 3(3): 247-256.

Itin, C. M. 1999. Reasserting the philosophy of experiential education as a vehicle for change in the 21 st century. Journal of Experiential Education 22(2): 91-98.

Kolb, D. A. 1984. Experiential learning: Experience as the source of learning and development. Upper Saddle River, NJ: Prentice Hall.

Lerner, R. 2004. Liberty: Thriving and civic engagement among America's youth. Thousand Oaks, CA: Sage Publications, Inc.

\section{For Further Information}

For more UC ANR publications and products, visit our online catalog at https://anrcatalog.ucanr.edu/ , call 1-800-994-8849, or write anrcatalog@ucanr.edu.

(C2021 The Regents of the University of California. This work is licensed under the Creative Commons AttributionNonCommercial-NoDerivatives 4.0 International License. To view a copy of this license, visit https://creativecommons.org/ licenses/by-nc-nd/4.0/ or send a letter to Creative Commons, PO Box 1866, Mountain View, CA 94042, USA.

Publication 8699

ISBN-13: 978-1-62711-176-8

It is the policy of the University of California (UC) and the UC Division of Agriculture and Natural Resources not to engage in discrimination against or harassment of any person in any of its programs or activities. (Complete nondiscrimination policy statement can be found at https://ucanr.edu/sites/anrstaff/ files/215244.pdf.)

Inquiries regarding ANR's nondiscrimination policies may be directed to UCANR, Affirmative Action Compliance and Title IX Officer, University of California Agriculture and Natural Resources, 2801 Second Street, Davis, CA 95618, (530) 7501343, titleixdiscrimination@ucanr.edu.

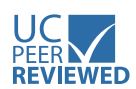

This publication has been anonymously peer reviewed for technical accuracy by University of California scientists and other qualified professionals. This review process was managed by UC ANR Associate Editor for 4-H Youth Development, Dorina Espinoza. 